\title{
Cash transfers and early childhood care and education in Zimbabwe: A critical inquiry to discourse, theory and practice
}

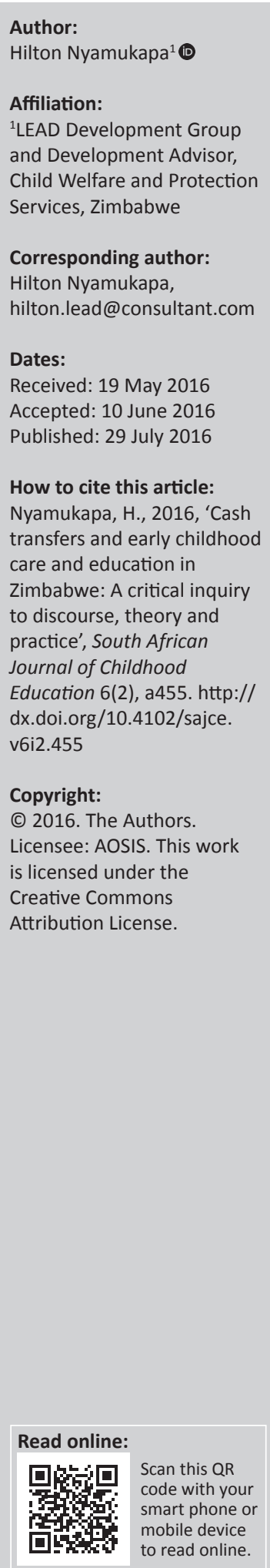

Cash transfer based social protection can potentially contribute positively upon targeted beneficiaries on a variety of developmental aspects. This study explored the pilot and scaledup phases of the Harmonised Social Cash Transfer program to determine impacts towards improving under-eight children's access to food, education, and health services. Stories of significant change were gathered in retrospect from purposively sampled caregivers and children beneficiaries. Based on thematic and guided analysis, it emerged that the programmes' theoretical and practical approaches renders the interventions less effective as impact assessment is narrowed to the early childhood cohort. This is furthered by relatively insufficient size of grants disbursed per household and commodity supply-side challenges. Consequently, a review to theoretical and practical tenets of the cash transfer approach becomes imminent in the Zimbabwean context. Targeting criteria needs refinement and supplemented with policy and multi-faceted public investment to address underlying limitations to impact on young children.

\section{Introduction}

Attention on early childhood care and education (ECCE) is important as it prepares children to understand and act upon their environment. This critical phase requires caregiver support to ensure the survival, adequate health, nutrition, and education of children. By realising the challenges faced by caregivers in supporting children, the government of Zimbabwe in 2011 commissioned a social protection strategy dubbed the Harmonised Social Cash Transfer (HSCT) aimed to lift poor families out of poverty while increasing consumption on health and education for children (Ministry of Labour and Social Services [MoLSS] 2011).

'Children' are defined as persons under the age of 18 in the Children's Act of Zimbabwe, and also in the HSCT. Childhood is often broken down into categories for planning various intervention strategies. Foetuses, toddlers, infants, and adolescents and some teenagers are all children. This study was motivated by the fact that these age groups, which all form children, have progressive, overlapping, and sometimes different sets of needs and therefore are likely to respond differently to the various interventions aimed at enhancing childhood as a whole. For example, the nutritional needs of newly born children are not the same as those of 13-year-olds. Therefore, defining access to food needs some elaboration, an age-based definition. On that note, the focus on early childhood as a particular cohort has often been silent in cash transfer programming in Zimbabwe, let alone has it been adequately evaluated and reported with relation to age-specific indicators (for example, Catholic Relief Services (CRS) 2011; MoLSS 2013; Oxford Policy Management 2013).

The various theoretical and practical assumptions inherent in the cash transfer programme pose some concerns over whether the intervention would be able to sufficiently meet the needs of very young children. However, recognising the uniqueness and delicacy of ECCE is important if meaningfully comprehensive approaches are taken towards developing, young children. This study specifically aimed to inquire the theoretical and practical relevancy and adequacy of cash transfers, especially, in addressing ECCE priorities and outcomes for the under-eight age group. The following were the guiding questions:

1. To what extent is the HSCT programme appropriate towards improving the access to food, education, and health of children under the age of 8 years?

2. To what extent is the HSCT adequate in improving the access to food, education, and health of children below the age of eight?

3. What are the theoretical and practical implications of the HSCT programme on ECCE? 
This article starts by locating ECCE within the bigger picture of cash transfer based social protection. This is followed by a review of income supports' targeting mechanisms and assumptions as they relate to young children. The theoretical orientation and methodology used in this study are argued, followed by a presentation of caregivers' and young children's lived experiences of cash transfers. This sets the stage for discussing theory, policy, and the practical implications of the cash transfer narratives towards enhancing the development of young children in Zimbabwe.

\section{Locating ECCE in cash transfer programming in Zimbabwe}

ECCE relates to a set of efforts towards ensuring child survival, health, nutrition, school readiness, and support for learning from conception to age eight. This definition, by description, has evolved from terms such as 'early childhood care' and 'early childhood learning' and 'early childhood development'. Though these terms are sometimes confused and used synonymously, they all relate to the context in which young children develop (UNESCO 2002). ECCE, in this article, is specifically confined to access to food, education, and health as key variables.

Cash transfers, on the hand, are non-contributory grants, such as income support, child grants and foster care grants, given to target beneficiaries to help them achieve a particular outcome. As the names of these cash disbursements suggest, some grants are aimed at generally lifting families out of poverty, to promote school enrolment, support food availability, and so on. Some transfers are actually a broad spectrum intervention, aimed at addressing several household challenges. The transfers can also be conditional upon the performance of some act by beneficiaries, or have no conditions at all but are still expected to address given problems. Obviously, the target population should suit some kind of criteria to qualify for the grants.

The use of cash in national social protection for children in Zimbabwe was rejuvenated under the National Action Plan for Orphans and Vulnerable Children (NAP for OVC) of 2004, which covered the 2005-2010 period (Ministry of Public Service, Labour and Social Welfare [MoPSLSW] 2005). At the onset of the HSCT, other long-standing government social assistance programmes, such as food and cash for work and assisted medical treatment order (AMTO), were not very visible due to lack of funding. Several other small scale cash based assistance programmes targeting children were being implemented by private organisations, such Goal Zimbabwe and Action Aid. Recommendations by partner organisations to the NAP for OVC, such as UNICEF Zimbabwe, saw the first cash transfer pilot project implemented under the Program of Support financing mechanism in 2009.

The pilot phase (between December 2009 and February 2012) was characterised by non-conditional and conditional cash disbursements in the Mashonaland East and Manicaland provinces, targeting poor households. The aim of the pilot project was improving the welfare of households and children in general with no specific reference to ECCE. However, the overall focus of its umbrella programme, the NAP for OVC, included support for birth registration, immunisation, and formal education, which can be reasonably expected to have inclusively benefited young children. The eligible households were to contain an orphan, be child-headed, and also contain a disabled or chronically ill person (CRS 2009). The disbursements per household were between 22 and 30 United States Dollars in every 2 months.

In 2011, an evaluation of the cash transfer pilot project, which reached 4083 households containing 12155 OVC, concluded that, compared to children in control households, children in households receiving cash transfers had improved on birth registration, vaccination, school attendance, and school material such as uniforms. However, a caution was issued about attributing such developments solely to the cash program because other interventions, such as vaccinations and school fees support, were implemented concurrently in the project area (CRS 2009). These results were part of the bases of scaling up the project in the second phase of NAP for OVC implemented from 2010 to 2015 (MoLSS 2011) as the HSCT Programme.

The HSCT was a thematic pillar in the NAP for OVC phase 2 to reach close to one-fifth of 250000 households identified as labour-constrained and food-poor, in which estimated 750000 children live. A household was defined as: ... all members eating from the same pot and regularly staying at
the same house or homestead. (MoLSS 2010)

The programme was argued to be appropriate in a context in which the majority of households (78\%) were living below the absolute poverty line (MoLSS 2011).

Like the pilot project, HSCT programme's goal at impact level was to improve the livelihoods of poor households and children's nutrition, health, and education. The initial disbursements were made in 2012. However, impact reports produced to date had no disaggregated data on improvements made towards children, especially below the formal school going age (for example, CRS 2011; MoLSS 2013). This suggest that the impact on ECCE remains an assumption, arguably positioned by impacts realised in other similar programmes from countries like Brazil, Nicaragua, and Zambia.

Several articles discuss and argue for the potential of cash transfers in improving children's access to education, health, and nutrition. Conditional cash transfer-based programmes such as The Red de Protección Social Programme in Nicaragua were reported to have resulted in an average increase of 18 percentage points in enrolment and 23 percentage points in attendance (against a baseline of $70 \%$ enrolment in the target population) between 2000 and 2003 (Maluccio 2005). Access to food improved and absenteeism declined by $16 \%$ during the first 9 months in the Kalomo district, Zambia, where an unconditional cash transfer was 
implemented (Schubert 2005). However, recent studies in sub-Sahara African countries indicate that food security is more pronounced at the household level, while indications for improvement in child nutritional status remain contested (De Groot et al. 2015:20). Despite the indications of beneficial effects, the approach needs deconstructing to explore its inherent hypothetical and practical assumptions in the Zimbabwean context.

\section{Targeting ECCE: Reviewing theoretical and practical approach of HSCT}

A reflection of several interventions and policies in Zimbabwe (including the Harmonised Cash Transfer program) around improving the welfare of children suggest a bearing on two main viewpoints or varying combinations of both. The first one is that children are underdeveloped because they live in income poor families (income approach). Secondly, children are underdeveloped because of an inability to access services attributable to structural failures, mainly the non-registration of births (deprivation approach). These conceptions have also directly or indirectly influenced cash transfer approaches in sub-Saharan Africa countries such as Ghana, Kenya, and Zambia, among others.

Practically, the exclusive targeting of young children in social protection is next to impossible. Young children are targeted through the households in which they live. Under this arrangement, the target itself is doubled, meaning that it includes both the household and the child. Firstly, targeting is aimed at selecting the eligible households based on household poverty or wealth index, for example. The second level will then determine whether the children within the households do qualify for the grant. Concerns have been raised as to whether targeting is based on household characteristics, such as the household wealth index, or whether the household is food-poor or labour-constrained will have an impact on children in Zimbabwe (Robertson et al. 2012). One study by (Robertson et al. 2012) compared targeting using household-based methods such as the wealth index, socio-demographic information, and labourconstrained households. The conclusion was that none is effective in reaching children with low social and educational outcomes. The methods cited are less than efficient and lack a comprehensive ability to identify needy and vulnerable children (Robertson et al. 2012). Instead, an additional level of targeting needs to incorporate the incidence of low child outcomes, such as the presence in the household of children not going to school. Such a conclusion was also arrived at in other studies on cash transfers in sub-Saharan Africa using 'labour constrained household' as targeting criteria (for instance, MCDSS \& GTZ 2006; Miller, Tsoka \& Reichert 2008). At the level of implementation, further challenges are introduced by household demographic and socio-economic relations within the households.

Addressing early childhood care and development through targeting and empowering households with regular cash transfers is a logical strategy as households are a baseline unit supporting children. But assuming that an increase in household income will translate to increased expenditures for the needs of children might be an oversimplification. The household is not an unproblematic unit. What is important is how the income is appropriated within the household, that is, who gets what and when.

The HSCT program, like other non-conditional cash transfers, assumes a traditional micro-economic model of households consisting of individuals who are utility maximising. In this model, the household make collective decisions and income is allocated in the best way to meet the needs of every individual member (Cornia \& Steward 1995; Thomas 1993). Under the utility model, even if the cash is disbursed to a household without any specific targeting, every member of the household is assured a fair share from the collective appropriation process. However, in reality, individuals within the household naturally have different priorities and preferences. By using food-poor and labour-constrained households as targeting criteria, a baseline survey carried out in ward 5 of the Goromonzi district indicated that $27 \%$ of total household members were either old, ill, disabled, or weak and are not fit to work (Team Consult 2010 in MoLSS 2010). The composition of the targeted households shows the presence of another high dependency group competing with the established $44 \%$ average household composition of children who are considered vulnerable. This translates to intense competition for resources among adults and children within the household and less room for utility maximisation at thev individual level. In this situation, the needs of children are most likely to remain unmet because of their low bargaining power.

In a more close observation, targeting ECCE with cash transfers rests on assumptions that include that a similarity exists between child poverty and household level poverty, the wealth index is an accurate predictor of poverty and vulnerability, income trickles down directly from the heads of households to children, and a perfect commodity supply exists. It is, therefore, important to understand how these assumptions intersect, in the experience of the beneficiaries, in order to determine the appropriateness and adequacy of the approach in addressing developmental needs during early life.

\section{Theoretical framework}

Cash transfer can be traced to the influence Sen's (1981) Entitlement Approach, which used the entitlement approach to explain the famine that occurred in Bengal in 1943. According to Sen, people did not die because of lack food but:

... lacked the ability [...] to command food through the legal means available in the society (Sen 1981:167), entitlement failure. Two types of entitlement failure were described, 'pull' and 'response' failures. Pull failures represents inability to demand, for example through wage loss in unemployment. Response failures represent inability to supply to meet demand, that is, the unavailability of food on the market. Cash transfer as basically a 
demand side based social protection strategy suggests an intervention aimed at mitigating the pull failures and transition from traditional supply side and charity based interventions. (Oxfam GB 2003)

The entitlement approach consists of three related concepts; the endowment set, entitlement mapping, and the entitlement set. The 'endowment set' is defined as the resources owned by a person (legal) both tangible and intangible. Examples are land, knowledge and skills, and labour power. It is these resources that, through either exchange or production, enable a person to obtain the other commodities needed for survival through means that are considered legal by one's society (Osmani 1993).

'Entitlement mapping' refers to the process of converting one's endowment into the means by which it is possible to obtain the commodities bundles of one's choice. Thus, labourers sell their labour to obtain wages for buying commodities, while farmers sell their produce to get cash for exchange with other commodities. Social security falls within this process. By targeting labour-constrained households, Zimbabwe's cash transfer program was actually recognising the constraints in entitlement mapping and alternatively supported household income.

The 'Entitlement set' (or commodity bundle), refers to the actual commodities which people chose for satisfying their needs (Sen 1981). The entitlement set also includes goods and services obtained through public provisioning such as free education.

Within the entitlement framework, it can be seen that the endowment set and the entitlement mapping process of caregivers is important for determining the support given to young children. Although most families in Zimbabwe are living in poverty, the household provision for children's needs, such as nutrition, health, and education, might be limited (MoLSS 2010). Improving household disposable income can easily improve living conditions, but the question is how this is relevant to the development of young children in all the essential faculties of their needs. This actually interrogates the process (entitlement mapping) of ability versus forgone opportunity costs in procuring the commodities (entitlement set) to meet the needs of young children.

The entitlement approach in this study forms the basis of analysing the interrelationships among the key variables and assumptions of the cash transfer programme. These include the intended purpose of the cash, various levels of targeting criteria, households and their composition, and the socioeconomic environment in which the programme exists among others. The indications for improvements in education were assessed on factors such as expenditures on preschooling and formal schooling, and access to related material. Health was assessed against incidents of ill-health, vaccination, and access to medical services. Access to food was analysed on its availability. It is important to note that other factors, such as the gender and age of caregivers, which are known to affect the overall impact of cash transfers on children (e.g. Slater \& Mphale 2008), were not accounted for.

\section{Study design and methodology}

A retrospective approach was utilised to produce the impact of data on non-predetermined indicators relevant to ECCE. Neither control groups nor repeated measures designs were employed. The initial data was gathered in 2011 from beneficiaries of the first pilot projects in the Goromonzi and Makoni rural districts. Another data set was gathered after the implementation of the HSCT program from the same locations in 2015. Study sites were chosen because poverty is more prevalent in rural households $(76.0 \%)$ compared to urban households (38.2\%) (Zimbabwe National Statistics Agency 2011).

Caregivers and children participated by narrating stories of 'most significant change' (or impacts) resulting from the cash transfer programs, followed by probing on impact of programmes on young children's access to food, education, and health. The most significant changes are the outstanding changes that happen or are realised by the beneficiaries as a result of an intervention (Davies \& Dart 2005). The underlying cognisance behind the method was that the intervention was intended to bring particular positive impacts to the target population. It is therefore reasonable to evaluate impacts in terms of the qualitative changes (intended and unintended) as reported by the beneficiaries, without using only predetermined set of indicators. Significant changes were also essential in improving the identification of the vdirect impact from the cash programme in a context of multiple interventions (Adatto 2008).

Stories from children were gathered in group discussions, simulating their day-to-day playing arrangement in the community. This design helped to capture their attention and ease the tension of one-on-one interviews. Children were guided to narrate significant stories related to the period of the transfers. Because of limited knowledge about how household income is spent, a starting point was what they could remember had been bought on the day the grants were received and the days immediately following. The scope of their observed trends in expenditures was then expanded to capture the commodities acquired to meet their needs.

The sampling procedure involved purposively identifying and drawing participants from households with children under the age of 8 who have benefited from cash transfer programing under the pilot and scaled-up phase of the HSCT. A total of 22 caregivers (8 male and 14 female) from 21 households and 17 children (10 boys and 7 girls) aged between 6 and 8 participated in the 2011 study phase. In 2015, a total of 20 households, of which 11 participated in 2011 and 9 were new, participated in the study. Of the 11 who participated in the 2011 study, four households had new caregivers as a result of deaths or migration. A total of 18 caregivers (9 male and 9 female) and a new set of 5 girls and 8 boys participated, 
replacing the previous ones who were now over age 10 . The sample was only a smaller percentage of the total number of beneficiaries and this may limit a generalisation of the findings. Nevertheless, basically, the greatest emphasis was on collecting dependable and transparent data that would give an insight into the cash transfer programming and its contribution towards improving ECCE.

Due ethical considerations were observed throughout the research process. Children's assent to participate was sought after obtaining the consent of their adult caregivers, who also participated in the study. This approach was convenient because caregivers and children were from the same households. It was clearly explained to participants that the research and the researcher were not part of the monitoring and evaluation process conducted by implementing agencies, and the research project was not directly aimed at making changes to the cash project. It was hoped that these assertions increased the likelihood of getting more honest reports of their experiences from the participants.

\section{Relevancy of HSCT to early childhood development}

The grand question relating to the relevancy of HSCT is whether it addresses the needs of children under age eight and is the best option, given the situation. The household provides the basic unit of support to children, especially during their early years. Income support to households may therefore lead to improvements in the welfare of children. Cash transfers are basically an important endowment, and entitlement mapping substitution is an effective medium of exchange for commodities. The data presented by the research participants suggest that the relevancy of cash transfers towards the development of children can be primarily traced to the demographic and socio-economic context of the household and the availability of commodities to satisfy their needs, as presented and discussed in the following section.

\section{Households, income appropriation and children's needs}

Households that participated in the study evidently met the targeting criteria of being food- poor, labour-constrained, and including a minimum of one vulnerable child, as prescribed by both phases of cash disbursements. The average number of occupants per participating household was 4.6.

Aggregated data from the total number of caregivers yielded expenditure in five major commodity sets as stories of most significant change. In composite rank order, they include expenditure on food, investment, debt servicing, blankets, medical attention, and other small purchases classified as general. This finding highlights some of the significance of cash transfers towards promoting ECCE. The commodity set does not necessarily reflect commodities that directly improve children's well-being in the early years, but largely represent commodities that collectively benefit the household. The major significant change in the stories of the children centred on the availability of food, clothes, uniforms, school stationery, and shoes. A more sound explanation, in this case, might consider labelling the significant changes as the priorities of children, which they can also use to gauge the relevancy of the cash transfers.

The caregiver and young children priority commodity sets converge strongly on food and far less on education, among other commodities. Food is therefore likely to be the most readily available commodity in the household. Such a disconnect in priorities raises a red flag regarding the direct relevance of the HSCT programme. Since caregivers allocate household income, and the bargaining position of children is often weak, there is considerable risk that the needs of children will be undermined, challenging the well-anticipated trickle-down effect.

Half of beneficiary caregivers who participated showed preference for spending the money in productive activities rather than only on consumption. One beneficiary noted:

'... buying some fertilizer or purchasing something for resale is better because I earn more ... The money multiples and I can buy more and diverse commodities out of the profit.' (beneficiary HSCT 2015)

The accumulation of endowment is therefore considered important for future provision to the household members. This leave cash transfers as a means to increase household consumption less relevant, at least in the short term. However, efforts in investing are also expected to inclusively benefit children when positive returns are realised in the long run. Prioritising and investing in agricultural production were also observed in an evaluation of the Zambian Child Support Grant (Handa et al. 2014). Investment in other productive assets, such as goats and chicken for breeding, was also noted among the participating caregivers.

The findings further indicate incidences of unmatched supply in terms of the accessibility and sometimes in the quality of the commodities. It was reported that education in the rural areas has compromised quality due to lack of textbooks and classrooms. Households with children of preschool going age in the Makoni district highlighted that they cannot afford the fees and also cited poorly equipped facilities with no qualified instructors. Close to $80 \%$ of caregivers who took part in both data-gathering sessions also reported that, although access to health care centres is hindered, they might be able to pay service fees, but the exorbitant transport charges are beyond what they can afford. Moreover, clinics or hospitals that are easily accessible are sometimes understaffed, and always out of essential medicines. This is consistent with the sentiments expressed in an earlier report from health authorities (Ministry of Health and Child Care [MoHCC] 2010:4). In Sen's terms, such response failures make the endowment of households less relevant to meet their needs, including the needs of children. The households might have the medium of exchange (cash), but the commodities are not be readily available to appropriately satify their needs. 
The impact identified among young children to cash transfers was not totally objective. In a development environment with intersecting resources feeding into household endowment, a margin of error is introduced in determining the contribution made by HSCT. Ten households who participated in 2011 had some of their children already on the Basic Education Assistance Module (BEAM), a national program that pays school fees for underprivileged children. Moreover, some participating caregivers had other sources of income. Twenty-five percent of the beneficiaries who participated in 2011 and 2015 do work for other villagers for pay or receive occasional remittances from relatives in the form of cash. The most significant attribute noted by $91 \%$ of participating households is the reliability of HSCT income compared to other sources, even though incidences of late disbursement were reported. However, the beneficiaries were sceptical about the continuity of the programme.

The relevancy of the HSCT towards improving early childhood is being challenged by household income appropriation priorities. Given the context of the uncomprehensive availability of commodities, the programme's relevancy is further threatened. The income support programme has, however, been welcomed as an addition to other support packages, such as the home-based care support for HIV and/ or AIDS patients. Implementing the cash transfer programmes may bring positive changes among children's welfare. Nevertheless, answers are still needed about the adequacy of the observed changes on access to food, health, and education services among the young children.

\section{Competing for entitlement: Cash transfers and ECCD outcomes}

Determining the adequacy of an intervention is not synonymous with determining its impact. Tracing impact has, in some cases, echoed the actual level of impact, which makes a real difference in the target population, especially the young children. The primary indication emanating from the stories of caregivers is that total household income, household composition, dependency load, and contesting priorities pose challenges to the totality of meeting the needs of children under their custody. The transfers averaging US $\$ 13$ per month were reported to be insufficient by $63.6 \%$ of the households who benefited from the pilot program. This figure includes $27.3 \%$ of the caregivers who could not identify significant changes but appreciated the grant as better than nothing. Seventy-five percent of the beneficiaries of the HSCT reported that the average disbursement of \$20 per month was insufficient to meet household needs, let alone allowing a reserve, specifically for children's needs. The inadequacy of income (equivalent of $\$ 6.5$ per month) disbursed under cash transfer programmes was also reported in Kenya's pilot cash transfer program commissioned in 2004 (Bryant 2009:68).

On the other hand, children mentioned requests for items such as school stationery that got no response or a delayed response. From the 17 children living in households who benefited from the pilot programme, six had no significant change story to tell or were not aware of the programme. The following sections present the findings and discuss the adequacy of cash transfers, specifically towards addressing the food, education, and health needs of young children.

\section{Access to food}

The major concern emerging from the caregivers and young people who participated in the study is the availability of food. There is a significant likelihood that household resource distribution is biased towards food procurement. If food is readily available to children as the household income increases, it may serve factors such as household size. The availability of food has been widely quantified as number of meals per day in both phases of Zimbabwe's cash transfer programme, as has been the case in other impact evaluations across Africa (e.g. DFID 2005:15, 18). There were no significant changes in the number of meals per day in participating households.

The dependency ratio of 2.29 and household size average of 4.1 used to determine the grant size of the pilot and HSCT programmes may not be a true reflection of the composition of rural households. About half of the households who participated in the study had more than three children, onethird with more than two adults. Thus, a uniform dependency ratio excluded many children eligible for support. Practically, the income received was spread among all children in the household past the 2.29 ratio, diluting the impact and diminishing its adequacy. Given the ceiling of the grant size, \$25 per household under the HSCT, if the number of household members exceeded the targeted four, it was found that all were surviving on the total available household income. The effects of household size on cash transfers were also reported in Ghana as a cause for concern (DakoGyeke \& Oduro 2013). However, as much as it appears obvious that the size of the households affects food adequacy, a cautionary note is that different methods of estimating consumption per person yield different results (Lanjouw \& Ravallion 1994).

From the children's perspective, an aggregated average of $60 \%$ who participated in both phases said food is not an issue of immediate concern to them and their households. These children looked satisfied by the amount of food available, though it is difficult to objectively attribute the adequacy solely to the cash intervention. A second subcategory concerning food is an aggregated figure of $33 \%$ of children who reported that food availability has improved in the household since the inception of the cash transfers. During data-gathering in 2015, an 8-year-old girl remembered her grandmother buying meat aa long time after receiving the cash transfer grant. This indicates potential improvement of the dietary diversity for children. The concern will be whether this improvement will remain occasional or become a permanent feature. The third sub-category is composed of children who could not particularly identify changes in the food status (11\% on aggregate) within their households before and after the income support programme. 
The quantity of food is however, not synonymous with its quality.

Food itself is a broad term; nutrition is more explanatory, especially for young children. Although the data on the actual nutritional value of the food accessed by households were neither gathered nor reflected in programme evaluation reports (foe example, UNICEF Zimbabwe 2013), it was evident that little attention is paid to what food is eaten and its nutritional value to children. Participating female caregivers, however, report occasionally making peanut butter available, citeing the recommendation by health officials. Basset (2008) in her article titled Can Conditional Cash Transfer Programs Play a Greater Role in Reducing Child Undernutrition? argued that cash transfers usually fall short of improving nutrition in young children. Her (Basset 2008) indication is that nutritional support as opposed to food availability, which should actually be a focus, and urged outside support to supplement children's nutritional requirements. Some studies suggest that poorly nourished children are more likely to be deficient in other outcomes, such as learning capabilities (Gani \& Prasad 2007).

\section{Early childhood education}

Education constitutes an individualised need of children, and stories from caregivers suggest that the age of a child is strongly related to the priority given to their educational needs:

'We need to consider children who are towards writing their public exams first ..., they require much in terms of fees and stationary and we also have to settle all our arrears with the school or they will be refused to sit for the exams.' (caregiver)

As educational priorities are given to older children, the younger children face the risk of not getting their educational needs met from within the household. Young children living in households without other, older children are therefore more likely to get educational support. The bigger picture on the prognosis on cash transfers towards ECCE, therefore, needs to be contextualised as noted by Schubert (2010). He (Schubert 2010) argued that a child-sensitive social protection approach in Zimbabwe and beyond does not have to ignore the needs of other categories of people (probably older children and adults) in the household.

A probe for further information related to the expenditure on the provision for children under the age of eight revealed that 90\% (aggregated from 2011 to 2015 data) of caregivers managed to send the children in their custody to school. Over the cash transfer era, the net primary school (6-12-year-olds) enrolment ratio has shown some improvement from a country average of 90 (UNICEF Zimbabwe 2009) to 93.1 in 2013 (Multiple Indicator Cluster Survey 2014). However, some caregivers established that their children's school attendance is not consistent as a result of the due inability and failure to pay tuition fees and other extra levies on time.
Of the seven major categories of children's stories that recounted significant change, three were related to education, namely, having school uniforms and shoes, and school fees paid, which came after food and clothes, with the general category coming last. An average of $70 \%$ of the children reported having a school uniform and school fees paid for them. Almost all reported having some school stationary acquired at some point, mainly exercise books, pens, and other accessories, but excluding textbooks. Of the total children interviewed, only one was not attending school, while 3 out of the total 25 who participated were not regularly attending school. There were no noteworthy differences in the stories of significant changes between boys and girls.

Since some children aged between six and eight from beneficiary households had already qualified for assistance through the BEAM, the complementary significance of cash transfers towards promoting education among children was greatly appreciated by caregivers. BEAM is a national programme assisting needy children with school fees. By 2015, the programme could cover children from the age five as the formal age of schooling was reduced from six. However, the BEAM programme does not cover pre-school education.

Insufficient pre-schools characterised the rural districts that were reached. Even though the current Education Statutes states that 4 years is the formal age of enrolment to primary school, caregivers reported that the schools in their areas lagbehind because of shortages of infrastructure and trained early childhood education teachers. The national net enrolment rate of 3-4-year-olds averages 30.7\% (Zimbabwe National Statistics Agency 2014). The figure is too low, signifying the inadequate early learning and school readiness infrastructure in Zimbabwe.

\section{Impact on health-related needs of young children}

Good health is undoubtedly a requirement for positive early childhood development. Although cash transfers go a long way in augmenting household food availability, it has been noted that household income remains relatively inadequate to cover medical expenses, especially for cases that require specialised treatment.

None of the most significant changes reported by caregivers and children was closely related to the health of young children. However, a further probe revealed that none of the child participants had been hospitalised for serious illness during the period of the programme implementation. Only a few (about one-fifth) of the caregivers have sought professional medical attention for children in their custody within the staggered span of the cash transfer programmes. Children's visits to health centres were mainly for regular vaccinations and monthly growth monitoring and health check-ups. For those who had illness-related consultations, some reported that they could not afford the prescribed medicines, excluding freely available antiretroviral drugs. 
A grandfather said he could not afford regular check-ups at the provincial hospital for his asthmatic granddaughter, aged seven. The majority of the caregivers (three-quarters) have treated their children at home using traditional medicine even for severe ailments such as tonsillitis, headaches, and diarrhoea. The major reason for home treatment is unavailable or poor-quality professional treatment at local clinics, which provide limited services and often lack appropriate medications.

The health concerns present little worry to caregivers and children, although they are aware that general physical wellness is important for their development. What makes health seem unimportant is not clear but the low incidence of ill-health among children and declining infant mortality rate is a plausible explanation for this trend. A scan of the trend data on the state of primary health care in Zimbabwe showed that immunisation against diseases has increased by $11 \%$ between 2005 and 2011 (Zimbabwe National Statistics Agency 2011:14). By 2011, at least $62.1 \%$ of children aged between 12 and 23 months, who live in rural areas, have received all major vaccines (Zimbabwe National Statistics Agency 2011). Since independence in 1980, the government of Zimbabwe, through the Maternal Child Health Care Programme, has been offering free medical services to children under the age of five (MoHCC 2011), a milestone towards promoting health in early childhood, even though there are notable challenges in staffing and medicines among other limitations.

\section{Conclusion and implications for theory, policy, and practice}

The harmonised cash transfer in Zimbabwe had the intention of improving the livelihood of households with significant impact upon children. However, empirical evidence generated by this study has identified several theoretical and contextual practical threats to the programme's relevancy and adequacy to the improvement of ECCE.

Targeting food-poor and labour-constrained households introduces conceptually adverse variables to the achievement of intended goals. The economically inactive adults present in the households actually represent a vulnerable population within households that compete with the identified vulnerable children. In fact, the dependency load on the received income becomes very high. Households are, therefore, often faced with competing priorities as to whose needs will be met at any given time. Subsequently, as revealed, households opt to prioritise commodities that meet the shared needs of all members, such as food and income generating investments. Even under such circumstances, the actual size of the household is a variable of concern.

Employing weighted averages, such as dependency ratios and household occupant ratios, also reduces the relevancy and adequacy of the grant in terms of realised impact, as the true figure may surpass expectations. When the actual number of household occupants falls beyond the operational limit used to determine size of grants, the available income is continuously diluted, sometimes beyond a level at which significant impact can be realised.

According to significant change stories from beneficiaries, the cash grants were likely to improve food availability but less sufficient in addressing key result areas on the health and education of young children. The availability of food was hailed, but the adequacy of its nutritional value, which is important for children, is not established. Although there were isolated cases of improvement in the diversity of food accessed by households, there was very little evidence pointing to securing dietary supplements for young children such as milk formulas. Children's enrolment at age six is quite high but school attendance ratio lags behind because the incomes of caregivers are not sufficient to meet extra requirements, such as stationery and development levies. On the other hand, access to health facilities has its own challenges in spite of low incidences of ill-health among the children. The reality of understaffed health centres that often lack enough essential medicines underscores the need for adequate cash transfers in comprehensively enhancing development in early childhood.

The above articulated complex interrelationships of imposed targeting criteria and household level-induced challenges clearly indicates how the relevancy and adequacy of the HSCT programme is undermined in the local context. These findings contribute essential information necessary for transforming targeting parameters, policy, and practice of income support programmes towards the development of young children.

Firstly, income support-based approaches towards addressing child poverty such as the HSCT need to ensure that the commodity supply infrastructure is able to handle induced demand. The success of the HSCT programme can only be rationally plausible if children subsequently access appropriate and adequate food, health, and education services. In fact, the local income support programs require augmenting by improving the supply of commodities necessary to fulfil children's needs. This implies a direct public investment in food security, primary health, and the education delivery system. For example, supplementary feeding, and enhancing the capacity of health centres and educational institutions, will go a long in improving access to and the quality of essential commodities for the development of young children.

Secondly, targeting households with income-based interventions may potentially yield a fragmented impact that falls below sufficient impact magnitudes. Practical considerations influence a number of issues. Households may have adults who can be more vulnerable (for example, the elderly and disabled) compete with children for the available resources. Furthermore, acknowledging that childhood is composed of different age categories with different developmental needs 
is another necessary step towards building precision in targeting. What is basically important is to adopt a more discretionary approach to determining the amount of grants in relation to the demographic characteristics and size of beneficiary households. Additionally, it may be more appropriate to target criteria based on the presence of adverse indicators, such as under nutrition, stunted growth and out of school children in the households.

Thirdly, the future consistency and continuation of cash disbursements under the HSCT is neither guaranteed nor expected by the beneficiaries. A significant number of beneficiaries who participated in this study reported using some of the proceeds to invest in income-generating projects. It is therefore plausible to consider stimulating and supporting household investment activities rather than structurally replacing its livelihood with cash transfers. This improves the adequacy and sustainability of households' ability to provide for young children.

The overall national policy goals for peace, equality, infrastructure, and economic development cannot be ignored. Social and political stability, coupled with economic growth, provides an environment conducive to a multi-sectoral effort towards building a comprehensive approach to improving ECCE outcomes in Zimbabwe.

\section{Acknowledgements Competing interests}

The authors declare that they have no financial or personal relationships which may have inappropriately influenced them in writing this article.

\section{References}

Adatto, M., 2008, Integrating survey and ethnographic methods to evaluate conditional cash transfer programs, International Food Policy Research Institute (IFPRI) Discussion Paper No. 00810, IFPRI, Washington, DC.

Basset, L., 2008, Can conditional cash transfer programs play a greater role in reducing child undernutrition?, Social protection discussion paper No. 0835, World Bank, New York.

Bryant, J.H., 2009 'Kenya's cash transfer program: Protecting the health and human rights of orphans and vulnerable children', Health and Human Rights 11(2), 65-76.

Catholic Relief Services (CRS), 2009, Pilot project for cash transfers to support OVC in Zimbabwe, CRS, Harare.

Catholic Relief Services (CRS), 2011, Manicaland pilot cash transfer programme: Implementation and evaluation report, CRS, Harare.

Cornia, G.A. \& Steward, F., 1995, 'Food subsidies: Two errors of targeting', in F. Steward (ed.), Adjustment and poverty: Options and choices, pp. 82-105, Routledge, London.

Dako-Gyeke, M. \& Oduro, R., 2013, 'Effects of household size on cash transfer utilization for orphans and vulnerable children in rural Ghana', Academic Journal of Interdisciplinary Studies 2(1).

Davies, R. \& Dart, J., 2005, The most significant change (msc) technique: A guide to its use, viewed 5 May 2011, from http://www.mande.co.uk/docs/MSCGuide.htm
De Groot, R., Palermo, T., Handa, S., Ragno, L.P. \& Peterman, A., 2015, Cash transfers and child nutrition: What we know and what we need to know, Innocenti Working Paper No. 2015-07, UNICEF Office of Research.

Department for International Development (DFID), 2005, Social transfers and chronic poverty: Emerging evidence and the challenge ahead, DFID, London.

Gani, A. \& Prasad, B.C., 2007, 'Food security and human development', International Journal of Social Economics 34(5), 310-319. http://dx.doi.org/10.1108/ 03068290710741570

Handa, S., Seidenfeld, D., Davis, B. \& Tembo, G., 2014, Are cash transfers a silver bullet? Evidence from the Zambian Child Grant, UNICEF Office of Research bullet? Evidence from the Zam
Working Paper No. 2014-No. 08.

Lanjouw, P. \& Ravallion, M., 1994, Poverty and household size, World Bank Policy Research Working Paper No. 1332, World Bank, Washington, DC.

Maluccio, J.A., 2005, Coping with the 'Coffee Crisis' in Central America: The role of the Nicaraguan Red de Protection Social, International Food Policy Research Institute (IFPRI) Working Paper No. 188, IFPRI, Washington, DC.

Ministry of Community Development and Social Services (MCDSS) \& German Technical Cooperation (GTZ), 2006, Evaluation report: Kalomo social cash transfer scheme, GTZ, Lusaka.

Miller, C., Tsoka, M. \& Reichert, K., 2008, Targeting report: External evaluation of the Mchinji social cash transfer pilot, Centre for International Health and Development, University School of Public Health, Boston.

Ministry of Health and Child Care (MoHCC), 2010, National child survival strategy for Zimbabwe 2010-2015, MoHCC, Harare.

Ministry of Health and Child Care (MoHCC), 2011, Maternal and child health, MoHCC, Harare, viewed 4 October 2011, from http://www.mohcw.gov.zw/index php?option=com_content\&view $=$ article\&id $=25 \&$ Itemid $=67$

Ministry of Public Service, Labour and Social Welfare (MoPSLSW), 2005, National action plan for orphans and vulnerable children, MoPSLSW, Harare.

Ministry of Labour and Social Services (MoLSS), 2010, National action plan for orphans and vulnerable children phase II 2011-2015, MoLSS, Harare.

Ministry of Labour and Social Services (MoLSS), 2011, Lessons Learned from Ongoing Social Cash Transfer Programmes in Zimbabwe, Harare, UNICEF, Harare.

Ministry of Labour and Social Services (MoLSS), 2013, The Harmonized Social Cash Transfer (HSCT) in Zimbabwe: Evidence from the impact evaluation baseline survey, MoLSS, Harare.

Ministry of Labour and Social Services (MoLSS) \& UNICEF Zimbabwe, 2012, Zimbabwe Harmonized Social Cash Transfer Programme (HSCT): Analysis of the process and results of targeting labour constrained food poor households in the first 10 results of targeting labour constrained
districts, UNICEF Zimbabwe, Harare.

Osmani, S.R., 1993, The entitlement approach to famine: An assessment, United Nations University - World Institute for Development Economics Research (UNUWIDER) Working Paper No. 107, UNU-WIDER, Helsinki.

OXFAM GB Kenya, 2003, 'Cash Transfer Programming', OXFAM GB, Nairobi.

Oxford Policy Management, 2013, Qualitative research and analyses of the economic impacts of cash transfer programmes in sub-Saharan Africa, Zimbabwe country case study report, FAO, Rome.

Robertson, L., Mushati, P., Eaton, J.W., Sherr, L., Makoni, J.C., Skovdal, M., et al., 2012, 'Household-based cash transfer targeting strategies in Zimbabwe: Are we reaching the most vulnerable children?', Social Science \& Medicine 75, 2503-2508. http:// dx.doi.org/10.1016/j.socscimed.2012.09.031

Schubert, B., 2005, Social cash transfers - Reaching the poorest, GTZ, Lusaka.

Schubert, B., 2010, Child-sensitive social protection in Zimbabwe, UNICEF, Harare.

Slater, R. \& Mphale, M., 2008, Cash transfers, gender and generational relations: Evidence from a pilot project in Lesotho, Overseas Development Institute, London.

Sen, A., 1981, Poverty and famines: An essay on entitlement and deprivation, Oxford University Press, Oxford.

Thomas, D., 1993, 'The distribution of income and expenditure within the household', Annales d'Economie et de Statistique 29, 109-135. http://dx.doi.org/10.2307/ 20075898

United Nations Children's Fund Zimbabwe (UNICEF), 2009, Zimbabwe country information: Statistics, UNICEF, Harare, viewed 24 September 2011, from http:// information: Statistics, UNicef.org/infobycountry/zimbabwe_statistics.html\#0

United Nations Children's Fund Zimbabwe (UNICEF), 2013, The Harmonized Social Cash Transfer in Zimbabwe - Evidence from impact evaluation baseline survey, UNICEF Zimbabwe, Harare.

United Nations Educational Scientific and Cultural Organization (UNESCO), 2002, Early childhood care? Development? Education?, UNESCO Policy Briefs on Early Childhood.

Zimbabwe National Statistics Agency, 2011, Zimbabwe demographic and health survey 2010-11: Preliminary report, Zimbabwe National Statistics Agency, Harare.

Zimbabwe National Statistics Agency, 2014, Zimbabwe Multiple Indicator Cluster Survey (MICS), Zimbabwe National Statistics Agency, Harare. 